of reading, dissecting, casting, moulding, and observing living persons, is astonishing; and the success and importance of his researches will, I am satisfied, ensure him a place among the greatest names of the human race, although, like every other great discoverer and benefactor, he has been loaded with ridicule and abuse."

Candidus.

\title{
CASE OF POPLITEAL ANEURISM-OPERATION-CURE.
}

BY A. W. SHIPMAN, M.D.

[Communicated for the Boston Medical and Surgical Journal.]

Some time in the month of June, 1839, I was consulted by Nicholas Dyer, of Willet, Cortland County, N. Y., for a tumor in the ham of the right leg. The patient was about 30 years of age, of a good constitution, and a farmer by occupation. The history which he gave was, that in the month of A pril previous, he began to feel some pain and soreness in the ham, which he attributed to rheumatism, and accordingly used some domestic application, but without any effect. In May he discovered a tumor in the ham, for which he used some volatile liniment, but the swelling continued to increase, and he applied to Dr. Lyman Eldridge, of Cincinnatus, who advised him as to the nature of his disease, and recommended him to consult me. At the time I first saw him, which was about the 10th of June, I found a tumor occupying the popliteal space, as large as an orange; it was tender on pressure, and pulsated pretty strongly, which ceased when pressure was made over the artery in the upper part of the thigh. The leg was flexed and could not be extended, the attempt giving him great pain. The tumor was hot, and the skin inflamed over it, as well as the calf of the leg. The foot was œdematous and numb. He suffered much pain day and night, and the tumor was rapidly increasing in size; it was difficult for him to walk. Under these circumstances I did not hesitate to advise him to submit to an operation as soon as possible.

This I performed on the 18th of June, with the assistance of Drs. Eldridge, McWhorter and Briggs, of Cincinnatus, in the usual manner, at the upper third of the thigh. The artery was separated as little as possible from its surrounding connections, and one firm silk ligature applied. The pulsations in the tumor immediately ceased; it became reduced nearly one half in size; the leg and foot became cold and pale, with a slight increase in the numbness, which already affected the limb. Hot flaunels were placed around the leg and foot, and bottles of hot water to the foot and sides of the leg. In a few hours re-action came on, with an increase of temperature in the leg and foot. No untoward symptoms came on to interrupt the cure. The ligature separated on the 20th day from the operation, the wound healed, the tumor in the ham was absorbed entirely in the course of a month, the leg could be extended perfectly, and its strength returned in a few months. He is now, and has been, as well as before the disease made its appearance. 